\title{
Research on Vehicle Braking Energy Recovery System and Energy Recovery Calculation
}

\author{
Zhi-qiang Xu \\ Guangdong University of Science \& Technology , Dongguan, Guangdong, 523083, \\ China
}

Keywords: Vehicle braking, Energy recovery, Electric energy storage system.

\begin{abstract}
This paper introduces a design of electric storage type energy recovery system through vehicle braking to fulfill energy recovery. Besides, theoretical calculation is conducted on the saving rate. Experimental results show that this system can be used in vehicle energy recovery after braking, and the fuel saving rate can be accounted for $23.49 \%$. The calculation result is consistent with the experimental results. The development of this system is a successful attempt improving the vehicle's energy saving and emission reduction.
\end{abstract}

\section{Introduction}

The vehicle braking energy recovery as well as the utilization technology refers to, the vehicle that is in the state of brake or deceleration, which can convert a portion of kinetic energy firstly into other forms of energy with an additional device when it is in the state of brake so as to be stored in the energy storage device, assist vehicle to start, accelerate, or supply other electronic equipment ${ }^{[1]}$. Generally speaking, because the air energy storage system is not widely used, so there are three main kinds of storage energy: flywheel energy storage, hydraulic energy storage and electric energy storage. Among them, the air energy storage system is suitable for large vehicle with good working environment, its technical difficulty is to realize the coordination, between the ultra high pressure energy storage tank and the energy supply of energy storage tank. Mechanical flywheel storage system is more suitable for large vehicle with high starting and braking frequency, its technical difficulty is to research and develop the ultra high speed flywheel. The structure of flywheel energy storage type is bulky and cumbersome, when it is in high speed operation it still exists security risks. Hydraulic storage energy system can be used in a variety of large and small vehicles, the key difficulty is to develop the proportion energy storage device as well as the reversible composite hydraulic components (pump---motor), the structure of hydraulic energy storage requires hydraulic system to have high sealing quality, moreover, compared with the relatively large friction loss, it is also its defects. The electric energy storage system is suitable for all kinds of vehicles, the technical problem is to develop good performance and low cost of super capacitor or battery. By comparison, the electric energy storage type has the advantages of simple structure, convenient operation and precise control, etc. ${ }^{[2-4]}$.

Today, because of the aggravation of the air pollution, many countries have put the research, development and the manufacture of new energy vehicles to a very important position, in order to further improve the efficiency of energy saving and emission reduction. In this paper, it makes research on the overall design scheme of the braking energy recovery system of electrical storage energy vehicle, as well as the corresponding energy recovery calculation method. 


\section{General Design of Braking System}

When the vehicle is in brake state, the engine is working in idle state, if it does not have braking operation, vehicles can keep on moving because of the inertia force, that is to say, wheels can drive vehicles to move forward ${ }^{[5]}$; if it goes on with the braking operation, namely, the braking frictional torque of the brake can be balanced with the inertia torque of the vehicle, which can result in the inertial kinetic energy consumption. Electrical storage energy type braking energy recovery system can achieve make the inertia force of the vehicle not only drive the vehicle forward, but also can drive a set of brake energy recovery device when the vehicle is in the brake state, so as to drive the generator to work, converting the kinetic energy into electrical energy that can be stored in batteries, which can reach deceleration and braking, realizing the aim of reducing braking wear as well as recovering some of the energy, so as to enhance the fuel economy ${ }^{[6]}$. Figure 1 is the schematic diagram of heavy type vehicle system with braking energy recovery device.

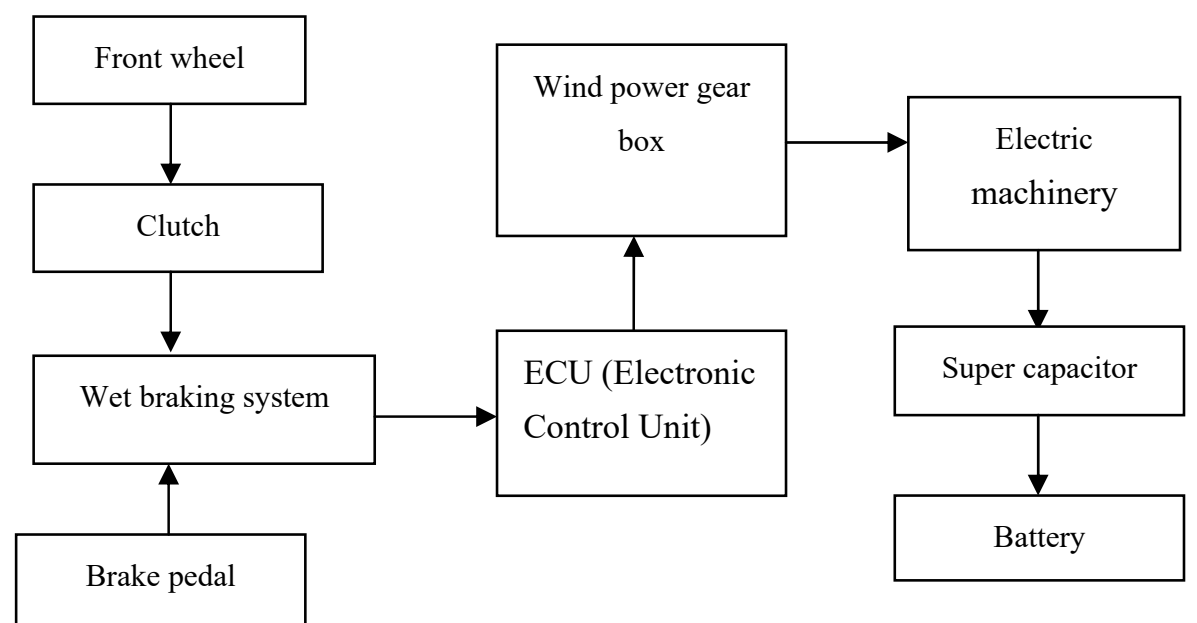

Fig. 1 Schematic Diagram of Vehicle System with Wet Braking Energy Recovery Device

Vehicle has large kinetic energy before braking, during the process of braking, it can consume up whole or part of its kinetic energy, while energy conversion device can achieve the conversation of part of the kinetic energy into other forms of energy that can be easily stored, instead of losing it. The braking energy recovery device discussed in this paper is a device that introduced a motor, during the process of braking, it can drive motor to make power, by means of the original kinetic energy of the whole vehicle through the transmission device, which can convert part of the original kinetic energy into electrical energy then store it up. In this way, it not only can share the kinetic energy consumed by the axle brake, but also can reduce the abrasion of the braking device, improve the braking efficiency, recover the dissipated energy as soon as possible, which can play a remarkable role in improving vehicle fuel economy.

\section{Theoretical Calculation of Recovery Energy}

Through the above dynamics analysis on the vehicle in the braking process, we can know that: the resistance force of moving in the braking process mainly includes rolling resistance force, air resistance force, gradient resistance force, the transmission resistance force, as well as the resistance force of mechanical braking device, while gradient resistance and transmission resistance force can be ignored under certain condition, therefore, it can only consider that vehicle is in the condition of rolling resistance force, air resistance force and braking force, moreover, during the process that the speed of the vehicle is fell from $v_{0}$ to $v_{l}$, the conversion relationship of energy can be shown in Formula 1: 
Among them

$$
\frac{1}{2} M v_{0}^{2}-\frac{1}{2} M v_{1}^{2}=w_{f}+w_{w}+w_{b}
$$

$v_{0}$ :initial braking speed, unit: $\mathrm{m} / \mathrm{s} ; v_{l}$ : the terminal velocity of braking, unit: $\mathrm{m} / \mathrm{s} ; w_{f}$ : the work of rolling resistance force, unit: $J ; w_{w}$ : the work of air resistance force, unit: $J ; w_{b}$ : the work of braking resistance force, unit: $J$;

The mathematical model of transmission system can be shown in Formula 2.

$$
\omega_{3}=\frac{i_{1} i_{2}\left(T_{e}+T_{m}\right)-F_{z} \varphi r+T_{\mu}}{i_{1}^{2} i_{2}^{2}\left(J_{e}+J_{m}+J_{1}\right)+\left(J_{3}+J_{2}\right) i_{2}^{2}+2 J_{s}+J_{5}+J_{4}}
$$

Among them

$J_{e}$ : the rotation inertia of engine; $J_{m}$ : the rotation inertia of motor; $J_{1}, J_{2}, J_{3}, J_{5}$ : the rotation inertia of each transmission gear; $J_{4}$ : the the rotation inertia of differential; $J_{S}$ : the rotation inertia of wheel; $T_{m}$ : torque of the motor; $T_{e}$ : torque of the engine; $\omega_{3}$ : the rotation speed of wheel; $\varphi$ : adhesion coefficient of road surface; $F_{z}$ : load of front axle; $T_{\mu}$ : braking torque of real wheel brake; $i_{1}, i_{2}$ : the transmitting ratio of transmission.

According to the force balance formula of whole vehicle (see Formula 3):

$$
M x^{\prime \prime}=\left(-F_{h}-f\right)
$$

Among them, $F$ : braking force; $x^{\prime \prime}$ : acceleration rate of the vehicle; $f$ : the sum of resistance force.

Because the braking process of whole vehicle is a very unstable process, there are a lot of factors that can have a certain impact on it. Here it can be assumed that the vehicle in in the state of braking, wet braking energy recovery device begins to enter the working state, under the premise that the maximum speed of motor, reversing conditions and other constraints can not be considered, assuming that it can adopt the ideal constant braking characteristics. When the whole vehicle is running at $v_{0} \sim v_{l}$, the braking force $F_{h}$ can be decreased with the increase of speed $v$; When the whole vehicle is running at $v_{l} \sim 0$, the braking force $F_{h}$ can be increased with the increase of the speed $v$; according to the force calculation of the whole vehicle during the process of running, it can get the following formulas:

$$
\begin{aligned}
& v_{0}-v_{1}: M x^{\prime \prime}=\left(-\frac{p}{x^{\prime}}-G f-\frac{C_{D} A x^{\prime 2}}{21.15}\right) \\
& v_{1}-0: M x^{\prime \prime}=\left(-K x^{\prime}-G f-\frac{C_{D} A x^{\prime 2}}{21.15}\right)
\end{aligned}
$$

\section{Experiment and Result}

The kinetic energy consume by air resistance force and rolling resistance force here can not be recycled and used; braking force can be including two parts, namely, mechanical braking force and braking force of energy recovery device, among them, the work of mechanical braking force can convert the vehicle's kinetic energy into heat energy, which is dissipated in the surrounding gas therefore, it can not be used; while the work of braking force caused by energy recovery device can convert into electrical energy, stored in the storage battery, which is a kind of energy that can be used, the braking energy recovery operation of heavy vehicle is mainly launched to this part. The theoretical calculation result of one-way energy recovery rate can be obtained based on the parameters of the table and above kinetic energy calculation formula, which can be shown in Table 1: 
Table 1 The Theoretical Calculation Result of Energy Recovery Rate

\begin{tabular}{|c|c|c|c|}
\hline $\begin{array}{c}\text { One-way fuel } \\
\text { consumption without } \\
\text { recovery device (L) }\end{array}$ & $\begin{array}{c}\text { One-way fuel } \\
\text { consumption of actual } \\
\text { saving }\end{array}$ & $\begin{array}{c}\text { Calculating the } \\
\text { saving of fuel } \\
\text { consumption }\end{array}$ & $\begin{array}{c}\text { One-way actual } \\
\text { saving rate }\end{array}$ \\
\hline 83 & 19.5 & 19.926 & $23.49 \%$ \\
\hline
\end{tabular}

The result showed us that the calculation of fuel saving is $19.926 \mathrm{~L}$, while the actual fuel saving is $19.5 \mathrm{~L}$, the generating error is caused by the increase of resistance force during the steering process of the vehicle, therefore, thus the calculation of formula also needs further improvement during the steering process.

\section{Conclusion}

In this paper, it proposed a braking energy recovery system additionally installed on the vehicle. This kind of energy recovery system does not require to change the original transmission system in a wide range, it can transfer the torque and rotation speed to the energy recovery system when the vehicle is in the braking condition, then it can convert the original part of the kinetic energy to electrical energy that can be easily stored in energy accumulator, so as to achieve energy saving, at the same time, in a certain extent, it can reduce the wear of vehicle's brake parts and prolong its service life. Under the circumstance that energy crisis, as well as environmental pollution is becoming increasingly serious, this kind of design is consistent with the purpose of saving energy and protecting the environment.

\section{Reference}

[1] Fiori C, Ahn K, Rakha H A. Power-based electric vehicle energy consumption model: Model development and validation[J]. Applied Energy, 2016, 168: 257-268.

[2] Fang K, Zhu X. A Research of Congestion Pricing to Beijing Traffic[J]. Journal of Applied Science and Engineering Innovation, 2015, 2(6): 216-219.

[3] Li Z, Cui X. Research on Location Problem of Electric Vehicle Charging Station[J]. Journal of Applied Science and Engineering Innovation, 2015, 2(12): 495-498.

[4] Hu X. Research on Application of Genetic Algorithm to AC Vector Control System[J]. Journal of Applied Science and Engineering Innovation, 2015, 2(12): 472-476.

[5] Gabriel-Buenaventura A, Azzopardi B. Energy recovery systems for retrofitting in internal combustion engine vehicles: A review of techniques[J]. Renewable and Sustainable Energy Reviews, 2015, 41: 955-964.

[6] Sharma M, Singh S, Shukla A K. Design and Fabrication of Kinetic Energy Recovery System-KERS in Bicycle[J]. International Journal of Engineering Science, 2016, 5045. 